\title{
Biological Agent Engineered Indicator
}

National Cancer Institute

\section{Source}

National Cancer Institute. Biological Agent Engineered Indicator. NCI Thesaurus. Code C158306.

An indication as to whether the biological challenge agent is engineered rather than naturally occurring. 